\title{
Relações entre violência doméstica e agressividade na adolescência
}

\author{
The relationship between family violence \\ and teenage aggressiveness
}

Stela Nazareth Meneghel 1

Elsa J. Giugliani 2

Olga Falceto 3

\footnotetext{
1 Escola de Saúde Pública, Secretaria de Saúde e Meio Ambiente. Av. Ipiranga 6311 Porto Alegre, RS 90610-001, Brasil.

2 Departamento de Pediatria, Faculdade de Medicina, Universidade Federal do Rio Grande do Sul. Rua Ramiro Barcel os 2600, 4 o andar, Porto Al egre, RS 90035-003, Brasil.

3 Departamento de Psiquiatria, Faculdade de Medicina, Universidade Federal do Rio Grande do Sul Rua Ramiro Barcel os 2350 , térreo, Porto Alegre, RS 90035-003, Brasil.
}

Abstract The following is an exploratory study on family violence in two different schools, public and the other private, Porto Al egre, Rio Grande do Sul. Seventy-six families were interviewed, 36 with adolescents classified as aggressi ve by teachers and 40 with non-aggressive adolescents. Total number of subjects was 213. Physical and severe violence, frequent or occasional, was present in more than half of the sample: 41 reports $-53.9 \%$. A third of the cases occurred in the privateschool (37\%), with twice as many in the public school (63\%). However, rates of severe or frequent episodes were similar in both schools. The relationship between violent behavior by teenagers and physical punishment by parents was significant. That is, aggressi ve adol escents were punished more than non-aggressive ones (odds ratio $=4.3$ ). Prevalence of physical abuse was higher in the older, male teenager group, in the presence of sibling aggression, and in lowincome and dysfunctional families. The study shows that physical abuse is more present in society than we would like to imagine.

Key words Domestic Violence; Adolescence; Battered Adolescents; School Heal th

Resumo Este é um estudo exploratório sobre violência doméstica realizado na ci dade de Porto Alegre, com al unos de duas escolas: uma pública e outra particular. Foram entrevistadas 76 famílias, 36 com adol escentes consi derados agressi vos pel os professores e quarenta com aqueles não agressivos, perfazendo um total de 213 pessoas. A punição físi ca grave, freqüente ou ocasi onal, foi um acontecimento presente em mais da metade da amostra: 41 relatos - 53,9\%. Um terço dos relatos (37\%) ocorreu na escola particular, e praticamente o dobro, na escola pública (67\%). Porém, episódios graves e freqüentes estiveram presentes em proporções semel hantes em ambas as escolas. A rel ação entre agressi vi dade na adolescência e punição físi ca grave foi estatisticamente signifi cativa. Isto significa que adol escentes agressi vos foram mais punidos que os não agressi vos (razão de chances $=4,3$ ). A prevalência de abuso físi co foi maior nos adolescentes do sexo masculino, mais velhos, na presença de violência entre irmãos, procedentes de famílias de baixa renda e rígidas. Este estudo mostrou que a punição física é um comportamento mais difundido na sociedade do que se poderia imaginar.

Palavras-chave Violência Doméstica; Adolescência; Adolescentes Maltratados; Saúde Escolar 
Introdução

"O homem mata o queama." Oscar Wilde

Nos últimos anos, está-se assistindo a um aumento 'epidêmico' dos fenômenos violentos na sociedade. A violência tem se mostrado com uma cara tão feroz quanto qualquer outro evento dito catastrófico (Muza, 1994).

Do ponto de vista da mortalidade, observase que as mortes violentas da Classificação Internacional de Doenças (CID), que englobam suicídios, homicídios, acidentes de trânsito e de trabalho, começaram a se tornar uma das causas mais importantes de óbito, não só em países desenvolvidos, mas também nos de Terceiro Mundo. No Rio Grande do Sul dos anos 80, elas constituíram, em média, a terceira causa de óbito. Considerando-se os “anos potenciais devida perdidos", nos quais se pondera no óbito o fator idade, verifica-se que as causas externas passaram a ocupar a primeira posição (Meneghel, 1986). Em outras palavras, atualmente, no Rio Grande do Sul, as mortes de maior peso social são as causadas pela violência, principalmente porque atingem adultos em idade produtiva e jovens.

A violência doméstica tem sido associada com agressividade infantil e delinqüência. Poderia a agressividade servir como um indicador que evidenciasse a presença de violência na família? Adolescentes agressivos são mais punidos que os demais? Estas são algumas perguntas que este trabalho procurou responder.

A agressividade entre crianças e adolescentes parece estar aumentando, porém este comportamento pode ser resultado de uma conduta menos repressiva em relação a este fenômeno. Por outro lado, os adolescentes podem estar mais violentos como resposta à violência estrutural da sociedade (Stith, 1993).

Outro aspecto sujeito a controvérsias refere-se à distribuição sócio-econômica da violência. Para alguns pesquisadores, a maior prevalência do problema está entre as classes menos favorecidas (Pelton, 1980). Outros, porém, afirmam que pessoas de qualquer classe social podem apresentar condutas violentas e que os mais favorecidos socialmente escondem seus comportamentos abusivos.

O objetivo principal deste trabalho foi estudar a associação entre o comportamento agressivo em adolescentes e presença de violência em suas famílias, procurando verificar se a agressividade poderia ser um indicador de violência doméstica. Além disso, pretendeu servir como instrumento de prevenção dos maus-tratos em crianças e adolescentes, denunciando, discutindo, criando alternativas, tentando fugir da burocratização e banalização do tema.

\section{O adolescente agressivo e maltratado}

"Se são violentos é porque estão desesperados." Marcuse

Conceitualmente, a violência pode ser considerada toda ação danosa à vida e à saúde do indivíduo, caracterizada por maus-tratos, cerceamento da liberdade ou imposição da força. A criança e o adolescente, por sua maior vulnerabilidade e dependência, são vítimas freqüentes de atos abusivos (Eisenstein \& Souza, 1993).

Agressão é qualquer forma de conduta direcionada visando prejudicar ou ferir outra pessoa (Kaplan \& Sadock, 1993). A agressividade faz parte do processo de conhecer, pode mediatizar-se, está dentro do nível simbólico, ao passo que a agressão não está mediatizada e, muitas vezes, encontra-se a serviço da destruição do pensamento (Fernandez, 1992).

Os conceitos de agressão e agressividade, assi m como o de violência, envolvem múltiplos enfoques e direcionamentos. Podem estar inseridos dentro de marcos referenciais biologicistas, comportamentalistas, dentro de modelos exclusivamente psiquiátricos ou de abordagens mais amplas, como a da violência estrutural, proporcionada pelo próprio sistema social com suas iniqüidades.

Autores adeptos das doutrinas biologicistas e comportamentalistas da agressão percebemna como "instintiva à natureza humana, tão natural eirresistível como a fomeeo instinto sexual. Eles tendem a transferir as regularidades do nível biológico para o social ea extrapolar os dados referentes aos animais para as rel ações humanas em sociedade" (Minayo, 1990a:19). Assim, a agressividade humana seria mediada geneticamente, resultante da natureza instintiva do homem que teria uma tendência irreprimível à violência e ao domínio dos outros, numa analogia à teoria da seleção natural .

Autores da linha psicanalítica (Chess \& Hassibi, 1982; Osório, 1982) tentaram identificar aspectos determinantes da agressividade na adolescência. Alguns consideram que o problema acontece devido a uma carência emocional experimentada pela criança que se sente ferida; outros acreditam que a criança não teve fixados os seus limites. Perceberam que crianças e adolescentes desvantajados, expostos ao abandono, morte ou doença dos pais, ou submetidos à intensa ansiedade gerada pelo ambiente das ruas, podem apresentar conduta agressiva (Fagan \& Wexler, 1987). Quando os pais ferem-se mutuamente, abandonam as famílias ou ameaçam suicidar-se, a ansiedade dos filhos é esmagadora. Eles podem desenvolver um padrão crescentemente agressivo em 
suas relações familiares, escolares e sociais (Wolff, 1985). Foi encontrada associação entre privação emocional na infância - agressão física entre os pais, depressão materna, quebra precoce do vínculo mãe-filho, negligência ou rejeição materna, número elevado de substitutos maternos, abuso físico e sexual - e conduta violenta em adolescentes (Forchand, 1991; Assis, 1991). Histórias de abuso físico e sexual têm sido relatadas por adultos e adolescentes que apresentam auto-imagem negativa, dificuldades de relacionamento e vazão inapropriada de impulsos agressivos (Dodge et al., 1991; Gil, 1990; Oates, 1984; Blomhoff et al., 1990).

Os compêndios de psiquiatria têm-se mostrado contraditórios, ambíguos e mesmo preconceituosos na abordagem do tema agressividade na infância e adolescência. Colocam uma ênfase maior nos aspectos legais da violência, principalmente quando envolvem danos à propriedade privada, em detrimento das condutas socialmente destrutivas aos jovens, adultocêntricas e patriarcais.

Outro grupo de pensadores percebe as condutas violentas como estratégia de sobrevivência das classes populares, vítimas das contradições do capitalismo no País. Jovens violentos podem pertencer a culturas marginais e apresentar comportamentos agressivos como forma de defesa, adaptação ao grupo ou ascensão social.

Nesta pesquisa optou-se pelo conceito que caracteriza a violência como um fenômeno em 'rede'. Entender a violência nesta dimensão significa percebê-la em suas múltiplas facetas, onde cada manifestação particular se articula com as outras: a violência dos indivíduos e dos pequenos grupos deve ser relacionada com a violência do Estado; a violência dos conflitos, com a ordem estabelecida (Minayo, 1990a). As instituições socializadoras, como família, escola, sistema judiciário, perpetuam os comportamentos violentos, na medida em que são responsáveis pela manutenção de papéis que condicionam os indivíduos a aceitar ou infligir sofrimento. "Tome-se como exemplo o assassi nato de adol escentes supostamente delinqüentes. Há que articulá-los com a violência estrutural que Ihes nega o possível social; com a violência do Estado, cuja face repressiva é quase a única que esses jovens conhecem; com a violência organizada dos grupos organizados de narcotráfico, que Ihes possibilitam realizar seus sonhos de afirmação, heroísmo e consumo, nutrindo-os com vantagens imediatas; com a violência individual de cada um que tenta se defender e se salvar sozinho numa sociedadeondeos direitos humanossão, para a maioria da população, um ideal a conquistar" (Minayo, 1990b:291).

A adolescência é uma etapa do desenvolvimento humano em que as patologias não são tão freqüentes, ou seja, espera-se que a morbidade neste grupo não seja elevada. Quanto à mortalidade, aproximadamente $70 \%$ dos óbitos nesta faixa etária são devidos a causas externas (SSMA, 1996). Os jovens do sexo masculino e negros são as vítimas preferenciais para mortes por homicídio, o que apresenta tendência ascendente principalmente nos grandes centros (M inayo, 1993). Comportamentos juvenis considerados agressivos incluem desde atos que os adultos classificam como criminosos, tais como roubo e assalto, até transgressões que têm relação estrita com a idade, como corridas de automóveis, brigas de rua e bebedeiras. Além disso, a valorização destes episódios irá variar de acordo com a cultura e as classes sociais. O DSM -IV (APA, 1994) não incluiu a categoria agressividade dentro dos distúrbios de conduta, que compreendem predominantemente violação a regras sociais. A agressividade, nesta última edição do DSM , faz parte da categoria transtorno no controle dos impulsos, definido como fracasso em resistir a um impulso ou tentação de executar um ato perigoso para si ou para os outros, resultando em agressões sérias ou destruição de propriedades, podendo estar associado à suspensão escolar ou detenções legais.

Nas escolas, o discurso é construtivista, embora a violência simbólica esteja explícita ou mascarada, e o aluno 'agressivo', que não se reenquadra nas normas vigentes, acaba expulso ou convidado a se retirar. "Os mesmos professores que, em teoria, consi deram que ser um bom aluno não tem nada a ver com submissão, valorizam positivamente situações que incluem a obediência erepetição, edesval orizam alunos em situações de agressivi dade, porque não se encaixam no modelo inconsciente do que é ser um bom aluno" (Fernandez, 1992). Caracterizar o comportamento de um jovem como agressivo na escola pode ser uma forma velada de violência, um estigma de desprestígio, que os discrimina no mesmo rótulo de marginalizados, delinqüentes, infratores ou perigosos.

Na família, a disciplina necessária na educação dos filhos fundamenta-se na idéia, culturalmente aceita, da dominação dos pais sobre os filhos, perdendo-se o limite entre punição física como norma educativa ou agressão (Eisenstein \& Souza, 1993). Consideram-se abuso as agressões inflingidas pelos pais no processo disciplinar dos filhos. Na definição de abuso físico estão presentes a intencionalidade 
e as conseqüências do ato agressivo, assim como os critérios de valor da sociedade. "A sociedade em que vivemos, com seu quadro de vioIência e destruição, não oferece garantias suficientes de sobrevivência ecria uma nova dificuldade para o desprendimento. $\mathrm{O}$ adolescente, cujo destino éa busca de ideais para identificar-se, depara-se com a violência e o poder etambém os usa" (Aberastury, 1981 apud Levisky, 1997).

Neste tema tão complexo e sujeito a vieses, fica difícil explicitar até aonde o adolescente está exteriorizando uma conduta 'agressiva' como uma reação de defesa à violência estrutural da sociedade, ou quando há uma intenção deliberada de infligir dano ou sofrimento a outrem. Em suma, em que momento eles são transformados de vítimas em réus. "A percepção da sociedadeem relação aos menores infratores é a de pivetes que roubam e matam, logo incomodam o bem estar-social. A sociedade os vê como agentes da violência. Pouco se fala destes indi víduos enquanto vítimas ou potenciais cidadãos" (Minayo \& Assis, 1993). O comportamento agressivo dos adolescentes certamente está articulado com as múltiplas formas de violência, explícitas ou não, que eles vivem no âmbito da família, da escola e de outras instituições da sociedade, muitas das quais com a função precípua de protegê-los.

\section{Considerações metodológicas}

"Eu não sei se tu consegues atingir além da casca da superficialidade." Pai, adolescente agressivo, escola particular.

Este é um estudo exploratório e fez parte de uma tese de doutoramento apresentada à Faculdade de Medicina, Universidade Federal do Rio Grande do Sul. A população da pesquisa foi composta por famílias de adolescentes considerados agressivos e não agressivos na escola. Foram selecionadas quarenta famílias de cada grupo, procedentes de duas escolas: uma pública, municipal, que atende população de baixa renda, e outra particular, com alunos de classes média e alta. Em cada escola, metade dos alunos era constituída de alunos agressivos e a outra metade de alunos não agressivos. A escolha dos adolescentes foi realizada na escola, pelos professores do Serviço de Orientação Educacional (SOE), considerando agressivo o aluno que envolveu-se em mais de um episódio de agressão física com colegas, funcionários ou professores. Episódios únicos e graves também foram consi derados.

Todos os adolescentes da escola particular foram entrevistados durante o período em que cursavam a oitava série, enquanto os da escola pública freqüentavam a sétima série, exceto quatro alunos com doze anos de idade que cursavam a sexta série.

Para coletar os dados, utilizou-se um roteiro semi-estruturado contendo em sua maioria perguntas abertas, acerca da vida familiar, conjugal, relação pai-filhos, rotinas, tarefas, lazer, vida escolar, conduta agressiva do adolescente e sistema de punições adotado pela família. Todas as entrevistas foram realizadas no período de março de 1992 a abril de 1993. Em cada família foram entrevistados, individual mente, o pai, a mãe e o adolescente selecionado. As entrevistas duravam, em média, de $30 \mathrm{~min}$ a 40 min por adulto e de $15 \mathrm{~min}$ a $20 \mathrm{~min}$ por adolescente. No momento da entrevista, a entrevistadora encontrava-se cega para a condição de agressividade do adolescente.

Durante a fase de coleta de dados foi escrito um Diário de Campo, à semelhança de pesquisas antropológicas (Salem, 1979; Zaluar, 1986).

A informação sobre as punições foi categorizada em punição leve ou ausente e punição grave. Punição leve ou ausente incluiu situações em que não havia punição física ou quando esta era pequena, simbólica ou leve (tapas; tapinhas; palmadas; palmadinhas; beliscões; empurrões; 'bifes'; chineladas; chineladinhas; solavancos; puxões; puxão de orelha; contenção pelo braço; cutucos; cascudos; sacudidelas; 'croques'). Considerou-se punição grave, quando houve menção a pelo menos um episódio contundente, grave, ou mesmo perverso (tundas, surras, pauladas, sarrafadas, cintadas, espancamentos; tapas e chineladas num contexto de maior gravidade, do tipo “dei uma surra de chinelo"; uso de instrumentos como chinelos, cintos, relhos, paus, mangueira, sarrafos, vassoura; locais pouco usuais e formas perversas de punição física, mescladas de sexualidade).

As famílias foram classificadas em flexíveis, quando havia um padrão de conduta grupal aberto, democrático e respeitoso, sem estruturação de respostas paralisadas e repetitivas; e rígidas, quando o grupo familiar mostrava-se fechado com predomínio de padrões de conflito e dominação (Falceto, 1989; Lewis, 1981).

Os dados coletados foram armazenados em computador utilizando-se o programa Dbase III. EpiInfo e SPSS foram utilizados na análise dos dados, que incluiu teste do Qui-Quadrado para testar associações entre as principais variáveis do estudo e o cálculo das razões de chance e intervalos de confiança para os riscos. Realizou-se regressão logística para testar a associação entre agressividade e punição, levando em consi deração possíveis fatores de confusão. 
Resultados: os números dos maus-tratos

"Vem de longe e promete não ter fim a guerra entre pais efilhos, a herança das culpas, a rejeição do sangue, o sacrifício da inocência." José Saramago

Foram entrevistadas 76 famílias, 37 cujos adolescentes eram procedentes da escola particular (48,7\%) e 39, da escola pública (51,3\%). Houve duas recusas entre as famílias da escola pública e quatro entre as da escola privada, perfazendo uma perda total de 7,9\%. Ao todo, foram entrevistadas 213 pessoas. A entrevista não foi realizada com 16 pais, cinco da escola particular e 11 da pública.

A distribuição da renda foi nitidamente diferente nas duas escolas. $\mathrm{Na}$ escola particular, dois terços das famílias (62,2\%) recebiam mais de vinte salários mínimos, enquanto na escola pública a renda de dois terços das famílias $(74,4 \%)$ estava abaixo de seis mínimos mensais.

A maioria das famílias entrevistadas (72,4\%) era constituída por pai, mãe e irmão(s). Em $12,3 \%$ das famílias havia a presença de apenas um dos pais e, nestes casos, o genitor presente era a mãe. Famílias refeitas, com a presença de um padrasto, constituíram 9,2\% da amostra. Doze famílias eram separadas e quatro mães eram viúvas, perfazendo um total de $21,1 \%$, em relação ao total.

A distribuição dos 76 adolescentes segundo sexo não foi homogênea, havendo praticamente o dobro de indivíduos do sexo masculino, ou seja, 48 rapazes $(63,2 \%)$ e 28 meninas $(36,8 \%)$, numa proporção de 1,6:1, que se manteve nas duas escolas. Embora as médias de idade dos adolescentes das duas escolas fossem semeIhantes - 14,3 anos na escola pública e 14,8 na particular -, a dispersão em torno da média na escola municipal foi maior. Entre os adolescentes entrevistados, 15 (19,7\%) exerciam algum tipo de trabalho remunerado, sendo a mai oria - 14 alunos - da escola pública. A distribuição dos adolescentes em relação à história de aleitamento materno mostrou que apenas $8,1 \%$ das mães da escola particular não amamentaram seus bebês, em contraposição a $30,8 \%$ das mães do bairro. No total, $53,9 \%$ das crianças foram cuidadas somente pela mãe no primeiro ano de vida e $26,6 \%$ estiveram em creches. Aproximadamente $80 \%$ dos alunos entrevistados da escola pública haviam repetido pelo menos uma das séries do primeiro grau. Na escola particular, o quadro inverteu-se: apenas cinco alunos $(13,5 \%)$ tinham história de repetência.

A classificação das famílias de acordo com sua dinâmica evidenciou uma quantidade maior de famílias flexíveis entre os alunos da escola particular $(46,0 \%)$, do que entre os da escola pública $(23,1 \%)$.

Encontraram-se nove situações de violência física entre os cônjuges ( $11,8 \%$ da amostra). Três (8,1\%) aconteceram em famílias da escola particular e seis $(15,4 \%)$ aconteceram nas da escola pública.

A violência contra os adolescentes foi expressa no indicador punição física grave. A punição física grave, episódio único ou freqüente, relatada por pelo menos um dos membros da família, ocorreu em 41 dos relatos, representando $53,9 \%$ do total de casos. Em apenas sete famílias, os três membros entrevistados negaram a existência de punição física. A maior parte das famílias, portanto, utilizava algum tipo de punição física em relação aos filhos, e o mais dramático é que na metade delas os castigos empregados eram graves. A situação mais séria foi a de famílias em que a punição era intensa e freqüente: 16 casos (18,4\%).

Aconteceram 14 relatos de punição grave entre os alunos da escola particular (37,8\%) e 27 entre os da escola pública $(69,2 \%)$, evidenciando que a punição física das crianças é um padrão de conduta mais disseminado entre as famílias de baixa renda. $O$ adulto mais punitivo foi o pai $(44,0 \%)$, enquanto as mães maltratantes perfizeram $21,9 \%$ da amostra.

Em aproximadamente $30 \%$ dos casos de punição física grave, os adolescentes ainda estavam sendo punidos no momento da entrevista. Destes, cinco eram da escola particular e oito da pública.

A análise bivariada que testou a associação entre punição física grave e algumas variáveis mostrou que os meninos, os mais velhos, os que trabalhavam fora e pertenciam a famílias de baixa renda foram os mais punidos. Outro aspecto da violência presente no contexto familiar foi o das agressões entre irmãos. Adolescentes punidos tiveram oito vezes mais chance de serem violentos com os irmãos. As famílias flexíveis foram menos punitivas com suas crianças, ou seja, adolescentes punidos tiveram uma probabilidade 15 vezes maior de pertencerem a famílias rígidas.

As variáveis que não estiveram associadas com punição física grave foram: primogenitura, aleitamento, cuidado materno no primeiro ano de vida, ausência do pai, repetência e punição física perpetrada pelos avós em relação aos pais.

A associação entre punição física grave e agressividade foi estatisticamente significativa - adolescentes diagnosticados como agressivos tiveram uma chance quatro vezes maior de serem punidos que os não agressivos (Tabela 1). 
Tabela 1

Agressividade e punição física grave segundo escola, Porto Alegre, 1992/1993.

\begin{tabular}{|c|c|c|c|c|c|c|}
\hline \multirow[t]{3}{*}{ Escola } & \multicolumn{4}{|c|}{ Punição física grave } & \multirow[t]{3}{*}{$\mathrm{p}$} & \multirow{3}{*}{$\begin{array}{l}\text { RC (intervalo } \\
\text { de confiança) }\end{array}$} \\
\hline & \multicolumn{2}{|c|}{ Sim } & \multicolumn{2}{|c|}{ Não } & & \\
\hline & $\mathrm{n}$ & $\%$ & $\mathrm{n}$ & $\%$ & & \\
\hline \multicolumn{7}{|l|}{ Particular } \\
\hline agressivo & 10 & 62,5 & 6 & 37,5 & & 4,62 \\
\hline não agressivo & 4 & 19,0 & 17 & 81,0 & 0,007 & $(1,31 ; 42,57)$ \\
\hline \multicolumn{7}{|l|}{ Pública } \\
\hline agressivo & 16 & 80,0 & 4 & 20,0 & 0,140 & 2,91 \\
\hline não agressivo & 11 & 57,9 & 8 & 42,1 & & $(0,58 ; 15,51)$ \\
\hline \multicolumn{7}{|l|}{ Total } \\
\hline agressivo & 26 & 72,2 & 10 & 27,8 & 0,002 & 4,33 \\
\hline não agressivo & 15 & 37,5 & 25 & 63,5 & & $(1,48 ; 12,95)$ \\
\hline
\end{tabular}

Famílias em pedaços

“Ondehás dejuntar

os mil eum pedaços

decada homem?"

Giórgos Seféris

O principal achado deste estudo, certamente, foi a associação entre agressividade e punição física, ficando evidente que os adolescentes considerados agressivos na escola foram mais punidos que os não agressivos. Assim, ficou explícita a figura do adolescente agressivo e maltratado, violento e machucado. "Se são vi ol entos é porque estão desesperados." Essa associação esteve presente nas duas escolas, mas foi mais evidente na escola particular, onde a punição física talvez possa ser considerada um dos fatores predisponentes da agressividade futura do jovem.

Os resultados desta pesquisa deixaram claro que, na vigência de comportamentos agressivos em adolescentes, não se deve deixar de pensar em violência doméstica, ficando evidente que o adolescente agressivo na escola é um indivíduo maltratado. Embora a relação entre punição física e agressividade já tenha sido evidenciada em diferentes estudos (Gil, 1990; Kempe \& Kempe, 1983), outros autores consideram que a violência doméstica não tem sido citada como fator de risco para distúrbios emocionais em jovens (Assis, 1991). É tempo, portanto, de se olhar a violência doméstica e propor formas educativas alternativas no âmbito da escola, da família e da sociedade, para que esta sociedade “não precise se fundamentar na ética perversa que necessita promover a morte do novo, na figura deseus jovens" (Kayayan, 1992:16).
A punição física grave, episódio único ou habitual, relatada por pelo menos um dos membros da família, foi referida por mais da metade da população amostrada neste estudo. Num inquérito realizado com escolares no Estado do Rio de Janeiro, a autora referiu 52,8\% de punições físicas - episódios leves e graves (Minayo \& Assis, 1993).

A punição física foi mais prevalente entre as famílias da escola pública, embora a proporção de famílias onde aconteciam punições graves e freqüentes tenha sido semelhante nas duas escolas. O pai foi o adulto mais punitivo, contrariando outros estudos que apontam a mãe como o adulto mais abusivo (Deslandes, 1994).

Em muitos dos depoimentos, ao relatar episódios de punição física intensa, os pais mostraram-se muito emocionados. Choraram, afirmaram que não bateriam mais nos filhos, parecia que buscavam absolvição e alívio das culpas, pela confissão que a entrevista proporcionava:

“Eu batia nele. Meatacava e batia nele. Hoje não faço mais isso. Até machuquei ele batendo com o cabo da vassoura. Ficou marcado nos braços dele. Eu me atacava... (chorou)." Mãe, escola pública, aluno agressivo.

Houve situações de contradição entre os membros da família: os adolescentes afirmando que sofriam algum tipo de punição e os pais negando. Também aconteceu o contrário, fiI hos gravemente punidos negaram a situação, que foi relatada pelo genitor abusivo, corroborando estudos que afirmam que a criança vitimizada costuma manter-se calada, mantendose fiel ao adulto maltratante, muitas vezes o único vínculo afetivo que possui. Este compor- 
tamento pareceu mais comum nas formas graves de abuso quando mobiliza intensos sentimentos de vergonha, medo e culpa (Kempe \& Kempe, 1983).

"Batia muito nele. Ele me questionava e era quem mais apanhava. Eu perdia a cabeça. Ele tem o dom demefazer perder a cabeça. Sempre tinha alguma coisa que el efazia para meatacar. Respondia com alguma coisa que sabia que ia bater no fígado. Então eu ia para cima delee batia forte. Se eu vou bater, bato com força. Na cabeça. É chocante o visual: aquele homem batendo com força na cabeça do guri." Pai, escola particular, aluno não agressivo.

No depoimento anterior, o adulto abusivo projetava os aspectos agressivos no filho, percebido como provocador. Ele afirmou que o fiIho o fazia perder a cabeça e ele batia na cabeça do menino. Outros pais declararam: "Eu não me dou com esse filho"; "El e faz o sangue subir na minha cabeça”; “Ele tem o dom de me provocar". Isto para justificar atos abusivos e, em última instância, modificar a condição de vítima para a de ré.

A situação mais dramática foi a da violência mesclada com sexualidade, formas perversas de abuso:

“Minha mãe me dá de rel ho. Tira a roupa minha edo meu irmão e dá de rel ho." Adolescente não agressivo, escola pública.

“Ele me disse que te contou que eu bato nele... Sabe, eu peguei uma cinta edei umascintadas nele. Levei pro quarto. Baixei o abrigo, senão não dói, deixei el e só de cueca e dei umas cintadas. Devez em quando precisa, não é? De vez em quando tem que dar uns tapas, não é? O que eu vou fazer?" Mãe, adolescente não agressivo, escola pública.

Algumas famílias mostraram-se tão dilaceradas que parecia não ter sobrado nada a não ser a raiva. Agressões verbais, físicas, retaliações, jogos de poder e de fúria. Nas famílias punitivas, havia menos flexibilidade e diálogo, mais rigidez nas relações e papéis desempenhados, além de maior quantidade de conflitos entre os irmãos.

Muitos adolescentes punidos ainda estavam sendo maltratados. Esses alunos, e principalmente suas famílias, precisariam de um atendimento imediato.

“Tento falar com a minha mãe que eu já tô grande para apanhar assim. Ela batequando a gente faz arte. Surra de cinta. Não pode fazer barulho, ela fica braba. Ela acha que eu debocho dela. Daí ela me surra. Diz que eu provoco ela." Adolescente não agressivo, escola pública.

A dominação e o autoritarismo perpassavam muitos dos espaços da vida destes adoles- centes. A violência doméstica incorporada nos castigos e práticas educativas foi apenas um de seus aspectos. A violência está expressa nas discriminações de gênero, idade e raça, nas contradições entre discurso e prática dos adultos, na conduta das escolas, evidentemente mais acentuada no colégio público, e principalmente na violência estrutural da sociedade que fecha a estes jovens as portas da esperança.

Considera-se oportuno, e até esperançoso, finalizar com o relato de uma família não punitiva. Estas famílias também estiveram presentes neste estudo. Elas enfrentam problemas e crises, como qualquer outra família, mas procuram resolvê-los de forma mais aberta, flexível, democrática e, inclusive, bem-humorada.

"Acho que se deve cortar al guma coisa, mas alguma coisa leve. Não tenho penalidade drástica. O assunto aqui em casa é muito debatido. Eu acredito muito na conversa, até pel o fato de ser juiz. Senão a pena termina sendo uma vingança. Não é preciso ficar tudo tão bordado de punições." Pai, adolescente agressivo, escola particular.

\section{Considerações finais}

“ ... não me peça exati dão porque vou cometer erros, muita coisa eu me esqueço ou se distorce, não guardo lugares, datas, nem nomes; em compensação, nunca deixo escapar uma boa história." Isabel Allende

Esta pesquisa confirmou a idéia inicial de que adolescentes agressivos na escola teriam experimentado mais episódios de violência doméstica do que os não agressivos. Contudo, o mais estarrecedor foi verificar o quanto a punição física das crianças está disseminada na sociedade e é aceita como prática disciplinar de jovens e adolescentes.

Entrevistar os adolescentes foi mais difícil que entrevistar adultos, talvez porque os adultos sejam mais verbais, enquanto os adolescentes utilizam linguagem não verbal, expressões fisionômicas, sorrisos, gestos. Também são mais tímidos e desconfiados, temerosos de serem delatados. Esses adolescentes são aculturados pelos adultos, cooptados, punidos fisicamente, pressionados verbalmente, chantageados pelos pais ou familiares com os quais vivem, em nome da socialização, do bom desempenho escolar, das responsabilidades. Enfim, "para o próprio bem deles". Os adultos declararam-se cheios de boas intenções, mesmo quando estavam sendo violentamente punitivos e cruéis. Essas constatações levaram a autora, sentindo-se solidária com estes jovens, 
tantas vezes tão desprotegidos, a modificar a denominação inicial do estudo: Por que nossos adolescentes são tão agressi vos? para o agora evidente: Por que somos tão agressi vos com nossos adolescentes?, que se tornou o título de passagem durante o transcurso do trabalho, documentando a mudança de postura e de ponto de vista que aconteceu no processo da pesquisa.

A fantasia inicial de que as famílias se recusariam a participar do trabalho ou se calariam, de que o homem seria o membro mais arredio nas entrevistas, não se confirmou. Não só as pessoas participaram como se sentiram aliviadas com isso e muitas agradeceram a oportunidade de participar do estudo. Houve questionamentos em relação à profundidade e/ ou fidedignidade das respostas, embora estas dúvidas pudessem significar uma reflexão sobre o processo de trabalho.

“Ol ha, é engraçado. Na verdade, perguntas coisas bem pessoais. Já pensou, se eu desse pau neleia ter que te contar, eé uma coisa horrorosa. Ou ia ter que mentir que também éuma coisa horrorosa. Eu tenho uma rel ação com uma pessoa que quer se desenvolver intel ectual mente. Tu não ia metirar pedaços. Ia fazer alguma pergunta indiscreta. Mastrabalho científico é trabal ho científico. Eu não sei se tu consegues ultrapassar a couraça das defesas... ." Pai, adolescente agressivo, escola particular.

Ficou evidente que o trabalho com adolescentes em crise deve ser realizado junto à família. $\mathrm{O}$ adolescente com comportamento violento está denunciando alguma coisa, quer seja maus-tratos, abuso sexual, solidão, dor. Articulando-se com a família, a escola e a equipe de saúde somam esforços e, certamente, muitos nós poderão ser desatados. O papel do professor é valioso: identificando situações, encaminhando, ouvindo a família, acolhendo. Começa aqui a atuação interdisciplinar (Cruz Neto et al., 1993).

Considera-se oportuno comentar a mudança interna que ocorreu na pesquisadora. Nesta tarefa de coletar histórias de vida, compartiIhar emoções, dores e segredos, muitos foram os sentimentos que brotaram, porém, “... se invadi estas pessoas fui, concomitantemente, invadida por elas. Em suma, sei queinfringi normas de imparcialidade na coleta dos dados (...) parece me que o ponto central não é como proceder para atingir a imparcial idade mas anteso de explicitar, sempre que possível, o modo como foi conduzido o trabalho de campo" (Salem, 1979:63).

Estas histórias, tantas, estas famílias inteiras e aos pedaços, estes adolescentes machucados, tristes, marcados, estas dores e também as alegrias, foram fermentando na cabeça e no coração da pesquisadora para torná-la uma outra pessoa. A constatação da universalidade dos temas, "a lágrima na pelebranca, na pel eescura", o cinto que corre, a culpa, os preconceitos do lado de lá, do lado de cá, as tramas, a impotência e o começar de novo, porque, sem dúvida, chega-se à parede dos próprios limites. Limites que são o novo ponto de partida. No fim da jornada, ou, quem sabe, "na metade do caminho", percebo que, no transcurso da tarefa, obtive um pequeno, frágil, fugidio e volátil fragmento de conhecimento da mesma natureza, acredito, daquela força que "move o sol e as estrelas!".

\section{Referências}

APA (American Psychiatric Association), 1994. Diagnostic and Statistical Manual of Mental Disorders - DSM-IV. Washington, D.C.: American Psychiatric Association.

ASSIS, S. G., 1991. Quando Crescer é um Desafio Social: Um Estudo Sócio-Epidemiológi co sobreViolência em Escolares em Duque de Caxias, Rio de Janeiro. Dissertação de Mestrado, Rio de Janeiro: Escola Nacional de Saúde Pública, Fundação Oswaldo Cruz.

BLOMHOFF, S.; SEIM, S. \& FRIIS, S., 1990. Can prediction of violence among psychiatric impatients be improved? Hospital Community Psychiatry, 41:771-775. 
CHESS, S. \& HASSIBI, M., 1982. Distúrbios de conduta. In: Princípios e Práticas de Psiquiatria Infantil (S. Chess \& M. Hassibi, eds.), pp. 91-166. Porto Alegre: Artes Médicas.

CRUZ NETO, O.; SOUZA, E. R. \& ASSIS, S. G., 1993. Entre o determinismo e a superação: algumas considerações. In: O Limite da Exclusão Social: Meninos e Meninas de Rua no Brasil (M. C. Mynaio, ed.), pp. 117-124. São Paulo: Hucitec.

DESLANDES, S., 1994. Atenção a crianças e adolescentes vítimas de violência doméstica. Cadernos deSaúdePública, 10(supl.1):177-188.

DODGE, K. A.; BATES, J. E. \& PETTIT, G. S., 1991. Mechanisms in the cycle of violence. Science, 250:1.678-1.683.

EISENSTEIN, E. \& SOUZA, R. P., 1993. Situações de Risco à Saúde de Crianças e Adolescentes. Rio de Janeiro: Vozes.

FALCETO, O. G., 1989. Diagnóstico psiquiátrico de família. Revista de Psiquiatria do Rio Grande do Sul, 11:131-136.

FAGAN, J. \& WEXLER, S., 1987. Crime at home and the streets: the relationships between family and strange violence. Violence and Victims, 2:5-23.

FERNANDEZ, A., 1992. A agressividade: qual o teu papel na aprendizagem? In: Paixão de Aprender (E. Grossi, ed.), pp. 168-180. Rio de Janeiro: Vozes.

FORCHAND, R., 1991. The role of the family stressors and parent relationships on adolescent functioning. Journal of the American Academy of Child and Adolescent Psychiatry, 30:316.

GIL, E., 1990. Treatment of Adults Survivors of Childwood Abuse. California: Sage Publications.

KAPLAN, H. \& SADOCK, B., 1993. Condições não atribuíveis a um transtorno mental. In: Compêndio de Psiquiatria (H. Kaplan \& B. Sadock, eds.), 6a ed., pp. 577-587. Porto Alegre: Artes Médicas.

KAYAYAN, A., 1992. Violência e saúde. IX Conferência Nacional de Saúde. Brasília: Universidade Nacional de Brasília. Cadernos Descentralizando e Democratizando o Conhecimento, 9:13-17.

KEMPE, R. \& KEM PE, H., 1983. Child Abuse. Suffolk: Fontana Paperbooks.

LEVISKY, D. L. e cols., 1997. Adolescência eViolência Conseqüências da Realidade Brasileira. Porto Alegre: Artes Médicas, 1997.

LEWIS, J., 1981. A família do paciente. In: Psiquiatria na Prática Médica (G. Usdin \&J. Lewis, eds.), pp. 68-69. Rio de Janeiro: Guanabara-Koogan.
MENEGHEL, S. N., 1986. Vigilância das principais causas de óbito prematuro. Boletim da Saúde, 13:34-36.

MINAYO, M. C., 1990a. Bibliografia Comentada na Produção Científica Brasileira sobre Violência e Saúde. Rio de Janeiro: Escola Nacional de Saúde Pública, Fundação Oswaldo Cruz.

MINAYO, M. C., 1990b. A violência na adolescência em foco a adolescência descamisada. Cadernos deSaúdePública, 6:278-292.

MINAYO, M. C., 1993. O Limite da Exclusão - Meninos e Meninas de Rua no Brasil. Rio de Janeiro: Hucitec-Abrasco.

MINAYO, M. C. \&ASSIS, S., 1993. Violência e saúde na infância e adolescência: uma agenda de investigação estratégica. Saúde em Debate, 39:58-63.

MUZA, G. M., 1994. A criança abusada e negligenciada. Jornal de Pediatria, 70:56-60.

OATES, R. J., 1984. Personality development after physical abuse. Archives of Disease in Childhood, 59:147-150.

OSÓRIO, L. C., 1982. Síndrome delinqüencial: um estudo sobre a psicopatologia do adolescente. In: Infância e Adolescência (J. Outeiral, ed.), pp. 7486. Porto Alegre: Artes Médicas.

PELTON, L., 1980. Child abuse and neglect: the myth of classlessness. In: Child Abuse and Neglect Comission and Omission (J. V. Cook \& R. T. Bowles, eds.), pp. 87-96. Toronto: Butterworth and Company Limited.

SSM A (Secretaria de Saúde e Meio Ambiente), 1996. Estatística de Saúde - Mortalidade. Porto Alegre: SSMA.

SALEM, T., 1979. Entrevistando famílias: notas sobre o trabalho de campo. In: A Aventura Sociológica (E. Nunes, ed.), pp. 47-64. Rio de Janeiro: Zahar.

STITH, D., 1993. Can physicians help curb adolescent violence? Hospital Practice, 27:193-207.

WOLFF, S., 1985. Non-delinquent disturbances of conduct. In: Child and Adolescent Psychiatry (M. Rutter \& L. Hessor, eds.), 3a ed. pp. 400-423. Boston: Blackwell Scientific Publications.

ZALUAR, A., 1986. Teoria e prática do trabalho de campo, alguns problemas. In: A Aventura Antropológica (R. Cardoso, ed.), 2a ed., pp. 107-126. Rio deJaneiro: Paz eTerra. 